\title{
Experimental analysis of energy savings and hygrothermal conditions improvement by means of air curtains in stores with intensive pedestrian traffic
}

\author{
Tomas Gil-Lopez, Miguel A. Galvez-Huerta, Juan Castejon-Navas, Virginia Gomez-Garcia
}

Physics and Technical Services applied to Buildings, Environment and Urbanism, Madrid Polytechnic University, Avenida Juan de Herrera 4, 28040 Madrid, Spain

a b s t $\mathbf{r}$ a c $\mathbf{t}$

\begin{abstract}
Current worldwide building legislation requirements aim to the design and construction of technical services that reduce energy consumption and improve indoor hygrothermal conditions. The retail sector in Spain, with a lot of outdated technical systems, demands energy conservation measures in order to reduce the increasingly electrical consumption for cooling. Climatic separation with modern air curtains and advanced hygrothermal control systems enables energy savings and can keep suitable indoor air temperature and humidity of stores with intense pedestrian traffic, especially when located in hot humid climates. As stated in the article, the energy savings in commercial buildings with these systems exceeds $30 \%$.
\end{abstract}

\section{Introduction}

The main reasons of high energy consumption of the air conditioning systems in partially open stores is that they have to match an important thermal load due to the infiltration air that comes into the shop through the open door [1,2].

This situation is even harder in warm humid climates, for the cooling system also has to face the latent cooling load associated to high outdoor humidity content. When air conditioning is supplied with a direct expansion system, the evaporative unit control is adjusted to maintain a set point temperature. As the total thermal load exceeds the power capacity, the desired temperature is rarely reached, though the unit is continuously working at the maximum power.

Instead of vestibules or sliding doors, air curtain systems are an accepted solution to reduce infiltration for buildings in mild and moderate climates, even when complying with very strict standard requirements [3]. It consists in a fan placed over the entry that recirculates the air of the room and blows a downward jet to create an air barrier to external heat and, what is most important, outdoors moisture.
The purpose of this study is to carry out a thorough experimental analysis of the thermal loads and the hygrothermal conditions of a store with a high pedestrian traffic under three air conditioning situations: without climatic separation, with a conventional air curtain and with a high efficiency air curtain [4]. From the analysis, the adequate strategy for energy savings [5-7] and indoor conditions improvement is proposed [8-10].

\section{Material and method}

The object of study is a $200 \mathrm{~m}^{2}$ commercial store with $3.10 \mathrm{~m}$. ceiling height. It is located in Javea, to the East of Spain, close to the sea shore (Mediterranean Sea).

As in most wide open premises, the entrance is affected by the conjunction of two phenomena: free convection and pressure difference. Climatic separation via a traditional air curtain system is used in this case, it being the most effective way of eliminating the otherwise associated thermal loads.

In order to reduce energy consumption and maintain indoor air temperature within a comfortable range, it was decided to change the climate separation facilities. It was intended to maintain indoor hygrothermal conditions between 22 and $23{ }^{\circ} \mathrm{C}$ with a relative humidity of 55\% [11], when outdoor temperatures swung from 17 to $30{ }^{\circ} \mathrm{C}$ and the relative humidity between $60 \%$ and $90 \%$ [12]. The refurbishment of the existing air conditioning facilities would need to be done without temporarily stopping commercial activity. 


\subsection{Case studies}

\subsubsection{Description of the original situation}

As in commercial stores of the type, air conditioning is solved by a ceiling mounted direct expansion unit.

Due to the frequent door opening caused by an estimated pedestrian traffic of 100 passages per hour, a conventional air curtain establishes a necessary climate separation. Nevertheless and though the shop is fully air conditioned, almost every day during summer period, indoor air temperature occasionally raises up to $30{ }^{\circ} \mathrm{C}$ for periods of nearly an hour, with outdoor temperatures slightly over $30{ }^{\circ} \mathrm{C}$. Indoors relative humidity in such cases was kept below $50 \%$ due to the dehumidification performance of the cooling machine.

The electrical consumption for cooling, under these conditions, mounts up to $33.7 \mathrm{~kW} \mathrm{~h} / \mathrm{m}^{2}$ year. According to the official Spanish rating procedure (CALENER), this electrical consumption leads to an F qualification in final energy consumption for cooling [13]. This service represents the $20 \%$ of the energy use in small retail, whose typical global final energy consumption for this climate is $89 \mathrm{~kW} \mathrm{h/ \textrm {m } ^ { 2 }}$ year ( $181 \mathrm{~kW} \mathrm{~h} / \mathrm{m}^{2}$ year, for primary energy), which is similar to other European energy benchmarks [14].

To identify the reasons of such high electrical consumption and the causes of unwanted indoor air conditions, a preliminary study on the air curtains operation was conducted with the following results:

Due to an inefficient control system, jet velocity is usually inadequate. When air is supplied with low velocity, air curtain is far from isolating indoor air from the variable outside conditions, for the air stream does not reach the ground, so there are large energy losses, during winter as well as in summer conditions (Fig. 1a). Convection energy losses were produced by the flow of air through the opening at the top of the facade forced by the decrease of density of hot air.

On the contrary, an increase in jet velocity tends to produce an air collision with the ground (Fig. 1b). In this case, the mixture of air from outside to the inside also causes a significant heat loss.

This effect is strengthened due to positive pressure created by the continued use of air conditioning system. It causes a positive indoors air pressure that forces indoor air to go outside through the openings.

To effectively carry out its function of climatic separation, air curtains should maintain a proper discharge length whatever the external conditions of wind are. If the air curtain jet is too weak and the throw distance is short it does not prevent infiltrations. By contrast, excessive throw distance due to a strong jet can reduce efficiency by almost $50 \%$. In this case, high velocity and turbulent flow make the air curtain partially mix with outside air [15].

\subsubsection{Description of the proposed solution}

It is proposed to replace the original air curtain system by a higher efficient one in order to analyze the energy savings and the indoor hygrothermal conditions achieved. The comparison has been made with respect to the original situation and to an intermediate case without curtains, during the substitution process, when electric consumption and indoor conditions were also evaluated.

The climate separation is achieved by means of an air curtain Indac S150 (Biddle) placed in the existing door. This advanced equipment automatically eliminates turbulence created by fans using downstream guide vanes. This solution makes possible to maintain the jet convergent and rectilinear, allowing to vary the thickness of the jet, instead of controlling the velocity of discharge, as most systems do.

It recirculates air at the room temperature throughout the year. The supplied air flow rate is fixed for each fan position and the equipment adapts its velocity of discharge by a variation of the
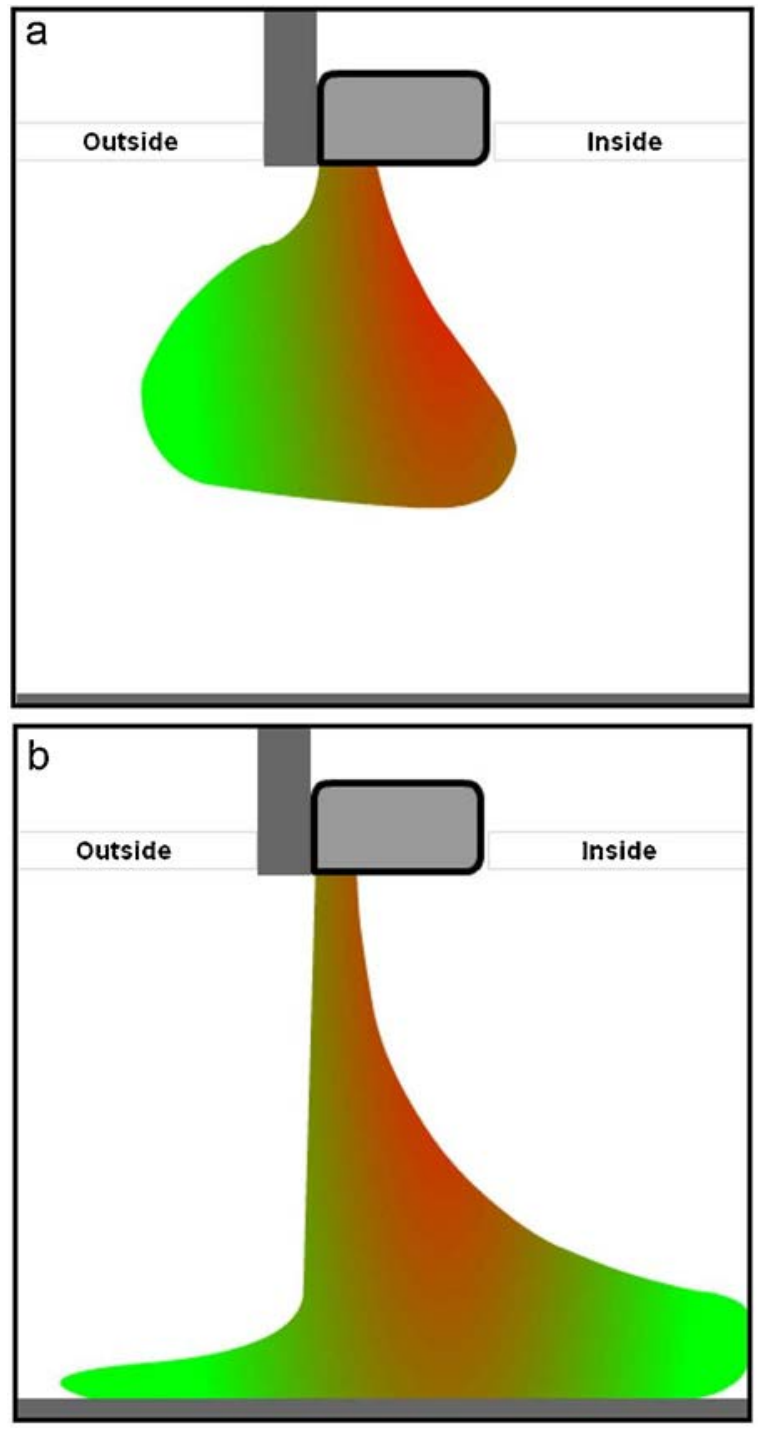

Fig. 1. (a) Short throw due to low velocity (Air flow rate: $1350 \mathrm{~m}^{3} / \mathrm{h}$; air velocity: $5 \mathrm{~m} / \mathrm{s}$; Jet momentum: $1.50 \mathrm{~N} / \mathrm{m}$ ), (b) Excessive throw when high velocity (Air flow rate: $1890 \mathrm{~m}^{3} / \mathrm{h}$; air velocity: $7 \mathrm{~m} / \mathrm{s}$; jet momentum: $2.95 \mathrm{~N} / \mathrm{m}$ ).

outlet geometry. Thus, an identical download length is achieved whatever the external conditions of wind are.

In summer case, the estimated electric power of the curtain is $64.6 \mathrm{~W}$, according to the specifications showed below (Table 1). This is almost four times smaller than for the fan of the original air curtain.

Air curtain characteristics have been selected (Fig. 2) by using a commercial simulation program that takes into account the effect of air flowing toward the outside due to difference of density [16].

To control and automate the installation (air curtain and direct expansion unit) a remote control and metering equipment was installed. It operated on the basis of a driver that control measures provided by four energy meters (general, air curtains, lighting and chiller), an interface for exchanging information with the VRF system and the corresponding control and warning relays.

Communication with the platform is maintained via GSM modem with security protocol. As the received data are stored, it is possible to draw graphics of electric power consumption related to outdoor conditions variation, as well as indoor temperature evolution curves.

The projected air conditioning system (Fig. 3) consists an existing ceiling mounted Mitsubishi evaporative unit with $7.1 \mathrm{~kW}$ 
Table 1

Air curtain fan electrical power consumption.

\begin{tabular}{|c|c|c|c|c|c|c|c|}
\hline \multirow[t]{2}{*}{ Electrical power consumption } & \multicolumn{7}{|c|}{ Strength level } \\
\hline & 1 & 2 & 3 & 4 & 5 & 6 & Rated \\
\hline Fan power consumption (W) & 64.6 & 95.2 & 115.0 & 158.2 & 206.0 & 282.3 & 282 \\
\hline Fan current draw (A) & 0.33 & 0.45 & 0.54 & 0.72 & 0.93 & 1.27 & \\
\hline
\end{tabular}

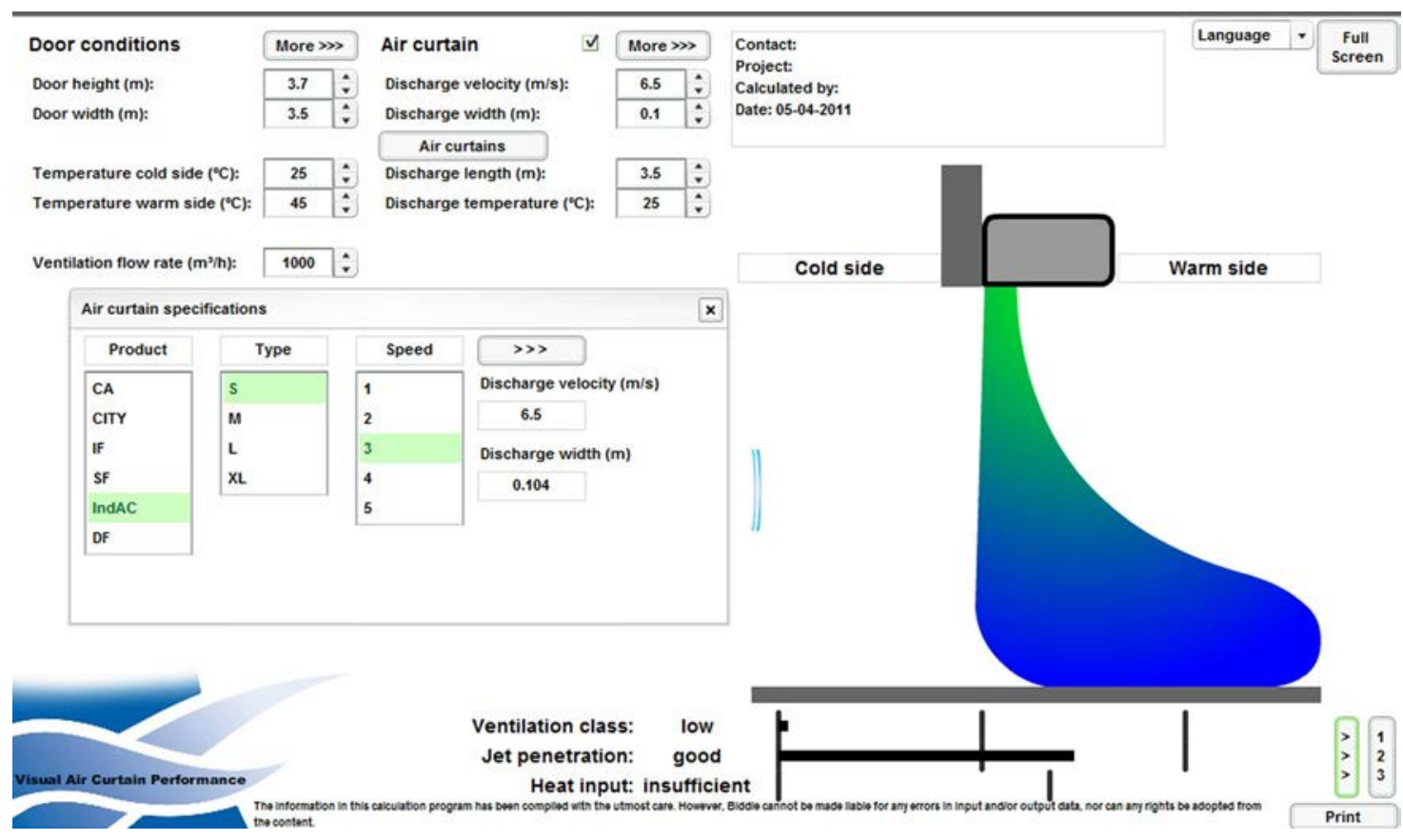

Fig. 2. Summer conditions air curtain selection.

cooling capacity (whose technical characteristics are shown in Table 2), a high efficiency Biddle air curtain and the aforementioned control system.

\subsection{Experimental test}

With the adequate measurement equipment (Fig. 4) outdoor and indoor hygrothermal conditions data were taken during the whole 2010 year (Fig. 5).
In addition, the refrigeration unit electrical consumption was monitored under the following situations:

(1) Air conditioning with the conventional air curtain during the period from September the 1st, at 11:50 am until September the 7th, at 20:00 pm.

(2) Air conditioning without climate separation, during the period running from September the 10th, at 10:30 am until September the $13 \mathrm{rd}$, at $13: 30 \mathrm{pm}$.

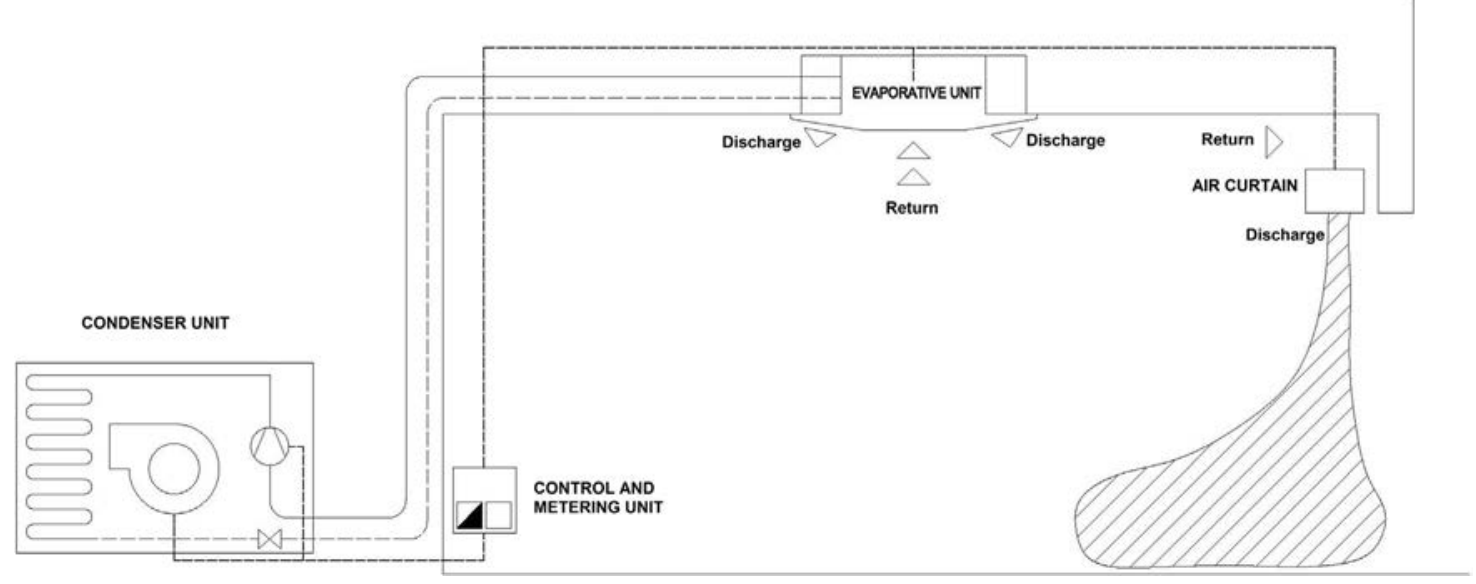

Fig. 3. Scheme of the proposed air conditioning system. 
Table 2

Direct expansion units technical data (Mitsubishi SPLZ-71BA).

\begin{tabular}{|c|c|c|c|}
\hline Mode & & Cooling & Heating \\
\hline Capacity & $(\mathrm{kW})$ & 7.10 & 8.00 \\
\hline Consumption & $(\mathrm{kW})$ & 2.53 & 2.49 \\
\hline $\operatorname{EER}(*)$ & $(-)$ & 2.81 & 3.21 \\
\hline Energy rating & & $\mathrm{C}$ & C \\
\hline Interior unit & & SUZ-KA71VA & \\
\hline Air flow rate & $\mathrm{m}^{3} / \mathrm{min}$ & $14 / 16 / 18 / 21$ & \\
\hline Exterior unit & & PLA-RP71BA & \\
\hline Air flow rate & $\mathrm{m}^{3} / \mathrm{min}$ & 49 & \\
\hline \multicolumn{4}{|c|}{$(*)$ Indoors operational conditions } \\
\hline Dry bulb temperature & $\mathrm{C}$ & 27 & 20 \\
\hline Wet bulb temperature & C & 19 & \\
\hline \multicolumn{4}{|c|}{ (*) Outdoors operational conditions } \\
\hline Dry bulb temperature & C & 35 & 7 \\
\hline Wet bulb temperature & C & 24 & 6 \\
\hline
\end{tabular}

(3) Air conditioning with a high efficiency air curtain during the period running from September the 30th, at 11:00 am until October the 5th, at 12:45 pm.

It is important to mention that an early autumn six days commercial week was selected to conduct the experiment, because it corresponds with a period of the year when hygrothermal conditions are close to annual media. Furthermore, due to the high humidity ratios, diurnal as well as annual thermal sway is small in climates such as the studied.

In order to compare the performance of the conventional and the high efficient air curtain and to quantify their contribution to the energy savings from the aforementioned experimental tests, the following analytical method has been used, expressed as an operational flow chart (Fig. 6).

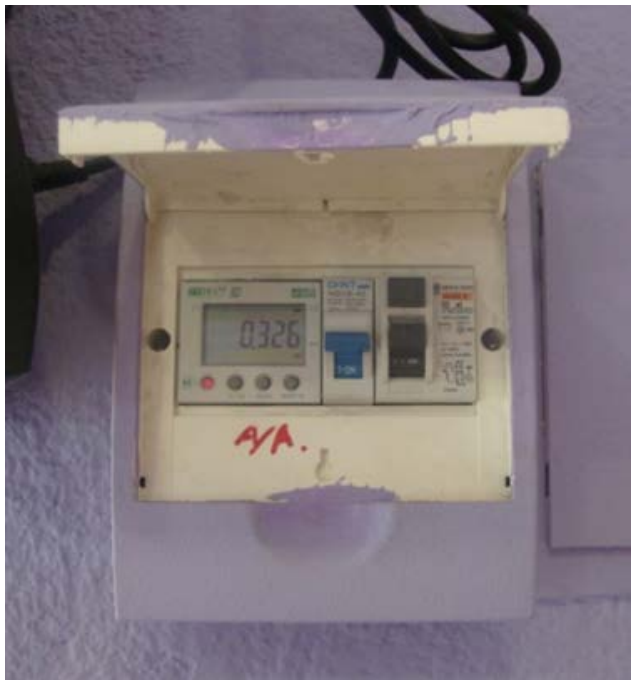

Fig. 4. Meteorological data meter.

\section{Calculation}

\subsection{External and internal cooling loads}

Thermal loads due to outdoor conditions have been calculated for the case without air curtain from the measured data of outdoor temperature and humidity, discriminated by 5 min intervals (Fig. 7). In the figure, absolute humidity $(\mathrm{g} / \mathrm{kg})$ represents the outdoor air vapor content. It has been calculated from the relative humidity measures taken by the datalogger. As outdoors humidity is maintained stable, the total thermal loads evolution follows the variations of outdoor temperature.

It has been estimated that the infiltration air flow enters through the door due to thermal draft [17]. With this air flow, the

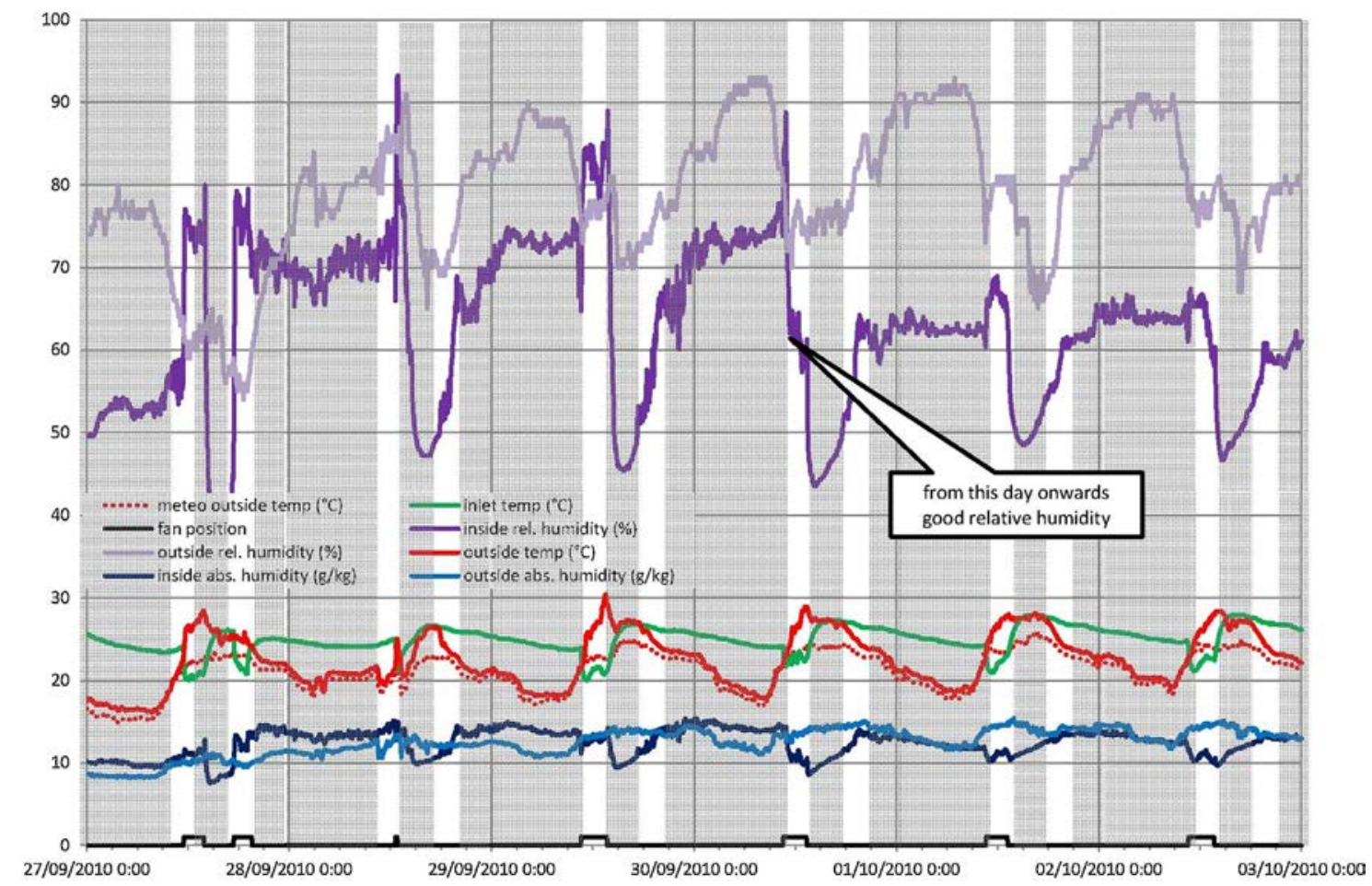

Fig. 5. Outdoor and indoor data with high efficiency air curtain system. 


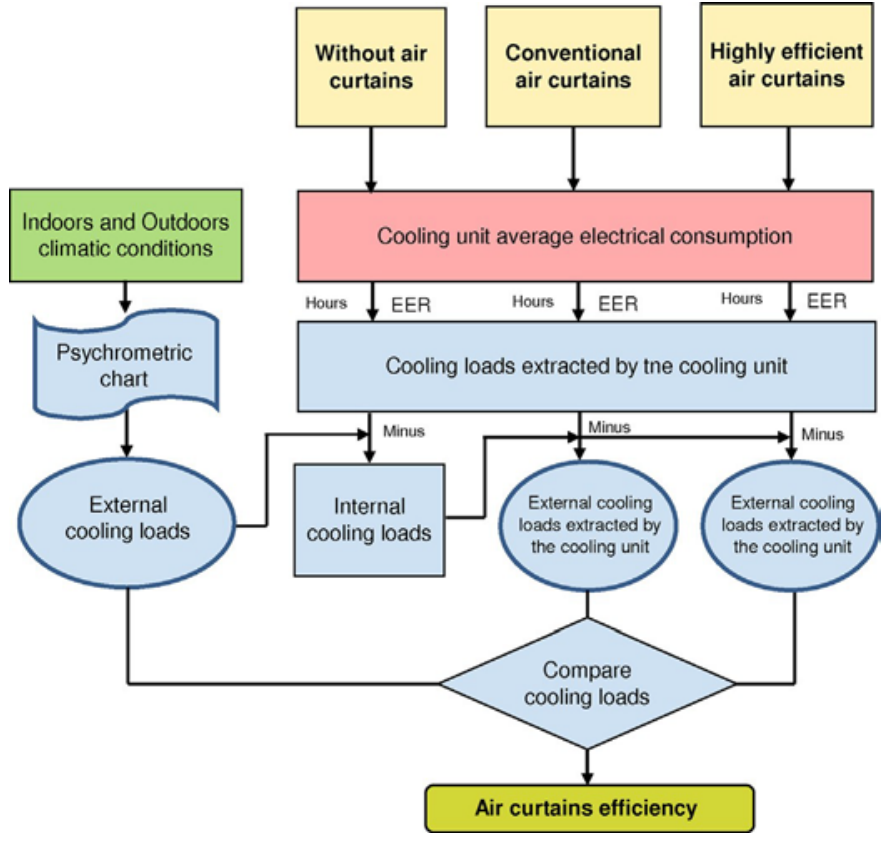

Fig. 6. Flow chart of the analytical method.

sensible and latent cooling loads to maintain indoors a temperature of $22.5{ }^{\circ} \mathrm{C}$ and a $55 \%$ relative humidity, which corresponds to a constant absolute humidity of $9.3 \mathrm{~g} / \mathrm{kg}$, have been obtained using well known cooling load calculation processes [18].

For the same situation, the thermal load extracted by the cooling unit during the $14.2 \mathrm{~h}$ of operation can be calculated. To do this, the average electrical power and the cooling energy efficiency ratio (EER) of the equipment, according to the experimental tests and the technical specifications, have to be considered.

\subsection{Air curtains efficiency}

The contribution of the air curtain to the reduction of infiltration is characterized by its sealing efficiency, ry [19].

$$
r y=1-\frac{Q_{\text {out, with air curtain }}}{\text { Qout, without air curtain }^{\text {C }}} \times 100 \%
$$

This dimensionless parameter is defined as the ratio between the sensible load through the door and the load in a reference situation (i.e., open door with no curtain). The lower the value of the efficiency, the greater the air infiltration or leakage. Medium efficiency of commercial air curtains approaches 0.5 , but due to maladjustments of air jet velocity, it can be as low as 0.3.

Different authors have provided the equations for the study of convection flows through open doors [20] and for the plane turbulent jet produced by air curtains [21]. Due to the difficulty of mathematical treatment [22] and the disparities with experimental measures, its interaction is seldom done by means of analytical equations. For predicting air curtains efficiency, 3D modeling tools like CFD programs, validated through experimental test, are nowadays widespread [23].

All these studies show that the efficiency of the air curtain device is related to the jet velocity, responsible for the throw and shape of the jet.

The parameter that best characterizes the operation of a curtain is the jet discharge momentum flux per length, $\mathrm{I}_{0}(\mathrm{~N} / \mathrm{m})$, that indicates the strength of the curtain [24]. It is defined by the expression:

$\mathrm{I}_{0}=\mathrm{p}_{0} \times \mathrm{d}_{0} \times \mathrm{U}_{0}^{2}$

being $\mathrm{p}_{0}\left(\mathrm{~kg} / \mathrm{m}^{3}\right)$ the air density, $\mathrm{d}_{0}$ the outlet width $(\mathrm{m})$ and $\mathrm{U}_{0}$ the outlet velocity $(\mathrm{m} / \mathrm{s})$.

Modern air curtains vary the air flow driven maintaining a constant flow rate by adapting the geometry of the discharge outlet (Fig. 8).

By choosing a relatively large outlet width, it can be achieved an optimum momentum, as needed to reach the floor, but with low velocity that keeps the flow in laminar regime.

Contrary to the traditional solution, in which the jet momentum is related to the supply air flow, in this case the control algorithm considers these variables separately. Thus, in order that the air jet completely covers the opening and climate separation is effective, the necessary jet momentum depending on the temperature difference is automatically calculated and the airflow and the thickness of the jet is conveniently adjusted, while velocity is maintained constant. Thus, the air stream always comes down without excessive energy cost.

In winter conditions, air curtains also are highly energy efficient terminal units and their coils permit a choice of the type of energy they run on, hot water included [25].

Although this is not the case of study, air curtain strength and heating can also be controlled independently (Fig. 9). When using this proportional automatic control system, the energy requirements can also be reduced by up to $60 \%$.

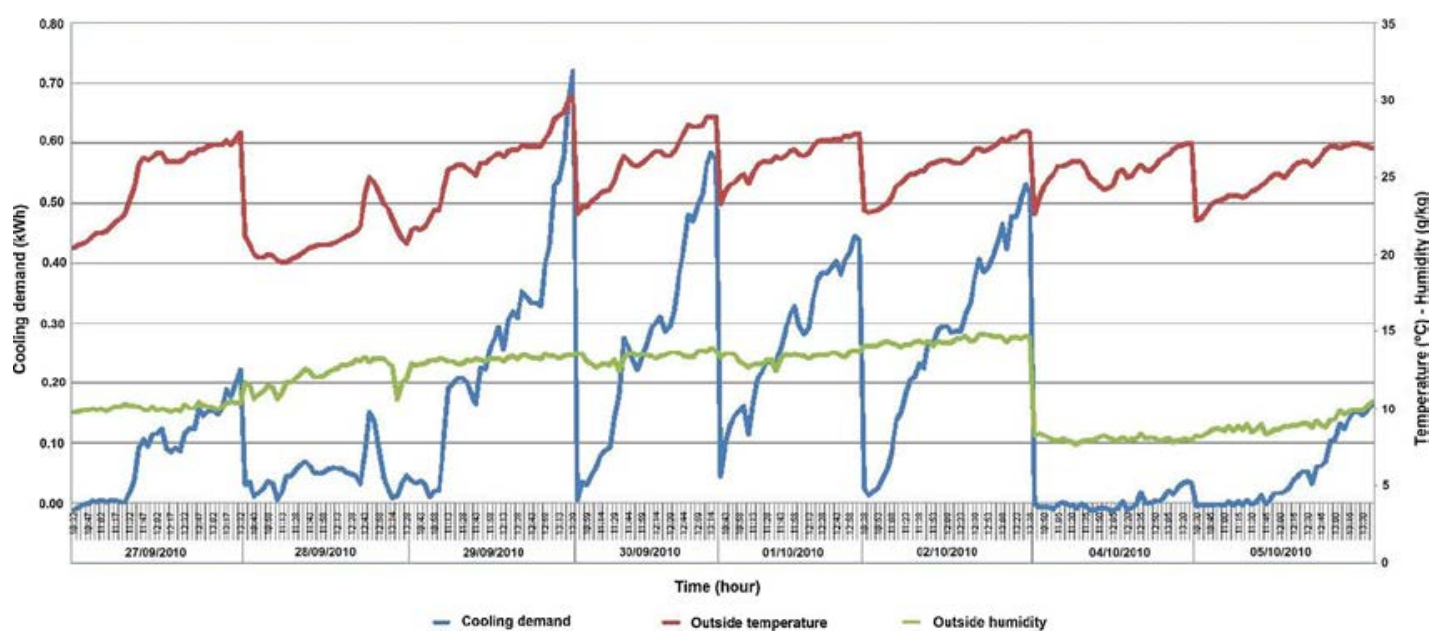

Fig. 7. Hourly evolution of air conditions. 

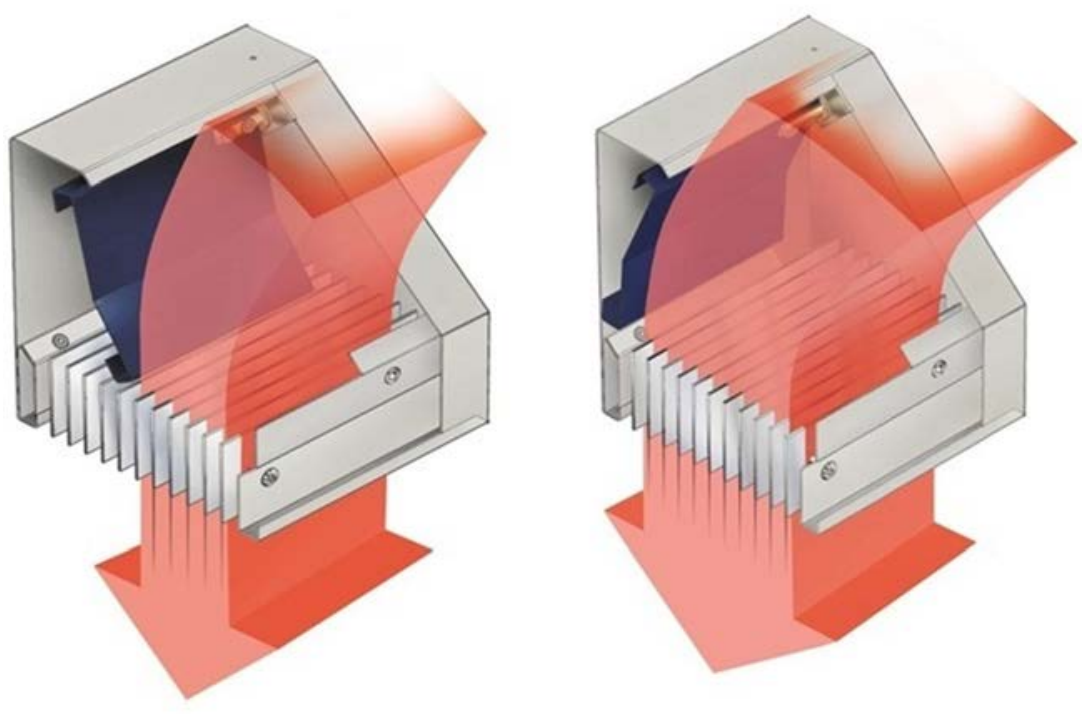

Fig. 8. Variable outlet width positions in an air curtain.

\section{Results and discussion}

\subsection{Electrical consumption of the cooling unit}

As it is shown in Fig. 10, when monitoring the refrigeration unit with the conventional air curtain system a total electrical consumption of $41 \mathrm{~kW}$ h was observed, which means an average power of $1.46 \mathrm{~kW}$, since it worked for $28 \mathrm{~h}$. To this consumption it should be added the fan of the curtain, whose power is estimated to be $207 \mathrm{~W}$.

During the period without air curtain the electrical consumption was $15 \mathrm{~kW} \mathrm{~h}$, which means an average power of $1.67 \mathrm{~kW}$, since it worked for $9 \mathrm{~h}$.
For the air conditioning with a high efficiency air curtain case the total electrical consumption amounted to $14 \mathrm{~kW} \mathrm{~h}$, which means an average power of $0.98 \mathrm{~kW}$, since it worked for $14.2 \mathrm{~h}$. To this consumption it should be added the curtain fan, and indicated above. As the fan always operates at position 1 during the hours of operation of the refrigeration unit, its consumption is estimated to be $0.96 \mathrm{~kW} \mathrm{~h}$.

\subsection{External and internal cooling loads}

The evolution of latent and sensible loads neutralized during the experimental tests can be seen in the following diagram (Fig. 11). It

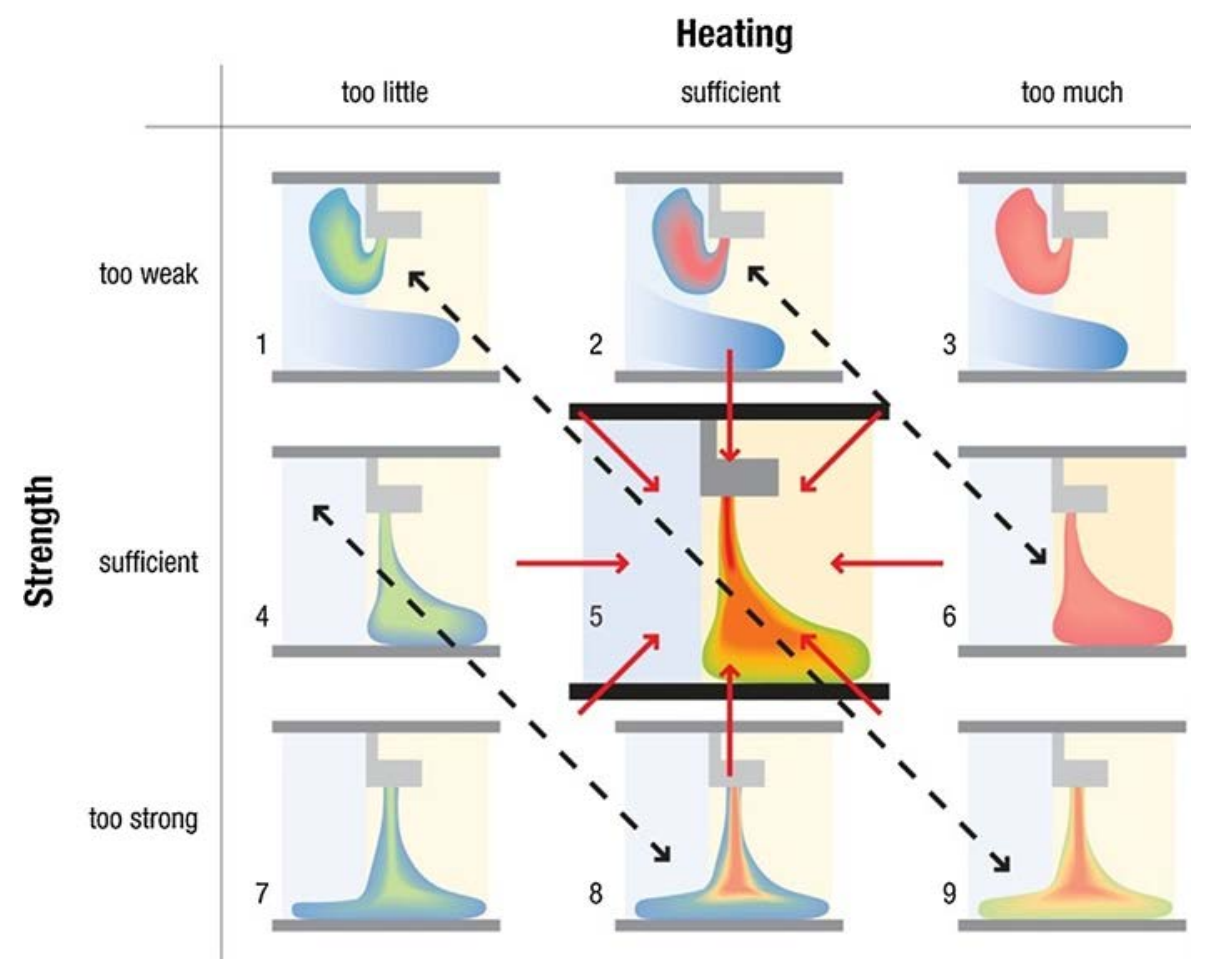

Fig. 9. Air curtain strength and heating control possibilities. 


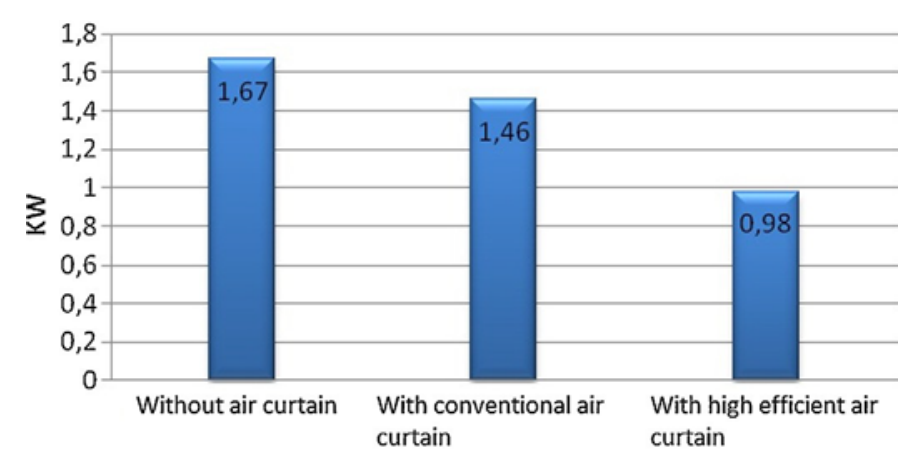

Fig. 10. Electric consumption of direct expansion cooling equipment.

is remarkable the high contribution of latent loads to the global thermal load. As it has been stated before in the article, this is the reason for being difficult to maintain indoor temperature in between the comfort range, in spite of the excessive electrical consumption of the direct expansion unit.

The integration of this demand over the five days period amounts to $28.93 \mathrm{~kW} \mathrm{~h}$, distributed as follows (Fig. 12).

The thermal load extracted by the cooling unit during the $14.2 \mathrm{~h}$ of operation is $66.63 \mathrm{~kW} \mathrm{~h}$.
The difference between the two results (66.63 vs. 28.93) equals the cooling load due to occupants and lighting. This demand can be considered constant and amounts to $37.7 \mathrm{~kW} \mathrm{~h}$. For the considered operating period, the average value for this load is $2.65 \mathrm{~kW}$. Since the store has an area of $160 \mathrm{~m}^{2}$, the resulting unitary load is $16.59 \mathrm{~W} / \mathrm{m}^{2}$, which is consistent with the values commonly used (10 W/m $\mathrm{m}^{2}$ for lighting and $7.5 \mathrm{~W} / \mathrm{m}^{2}$ for occupants).

\subsection{Conventional air curtain performance}

In the case of the conventional curtain, as the electric average consumption and the EER of the cooling unit are known, the thermal load extracted during the same period of time can also be deduced, which amounts to $1.46 \mathrm{~kW} \times 2.81 \times 14.2 \mathrm{~h}=56.26 \times \mathrm{kW} \mathrm{h}$. The internal loads again being excluded, it follows that the direct expansion unit neutralizes $56.26-37.7=18.56 \mathrm{~kW}$ h. Therefore, in this case the efficiency of conventional curtain is $35.8 \%$.

\subsection{Highly efficient air curtain performance}

As the power consumption with high efficiency curtain is known, $14 \mathrm{~kW}$ h, the heat load extracted in this case by the refrigeration unit during the operating period, considering an EER of 2.81, can be deduced, and amounts to $39.34 \mathrm{~kW} \mathrm{~h}$. If the fixed internal

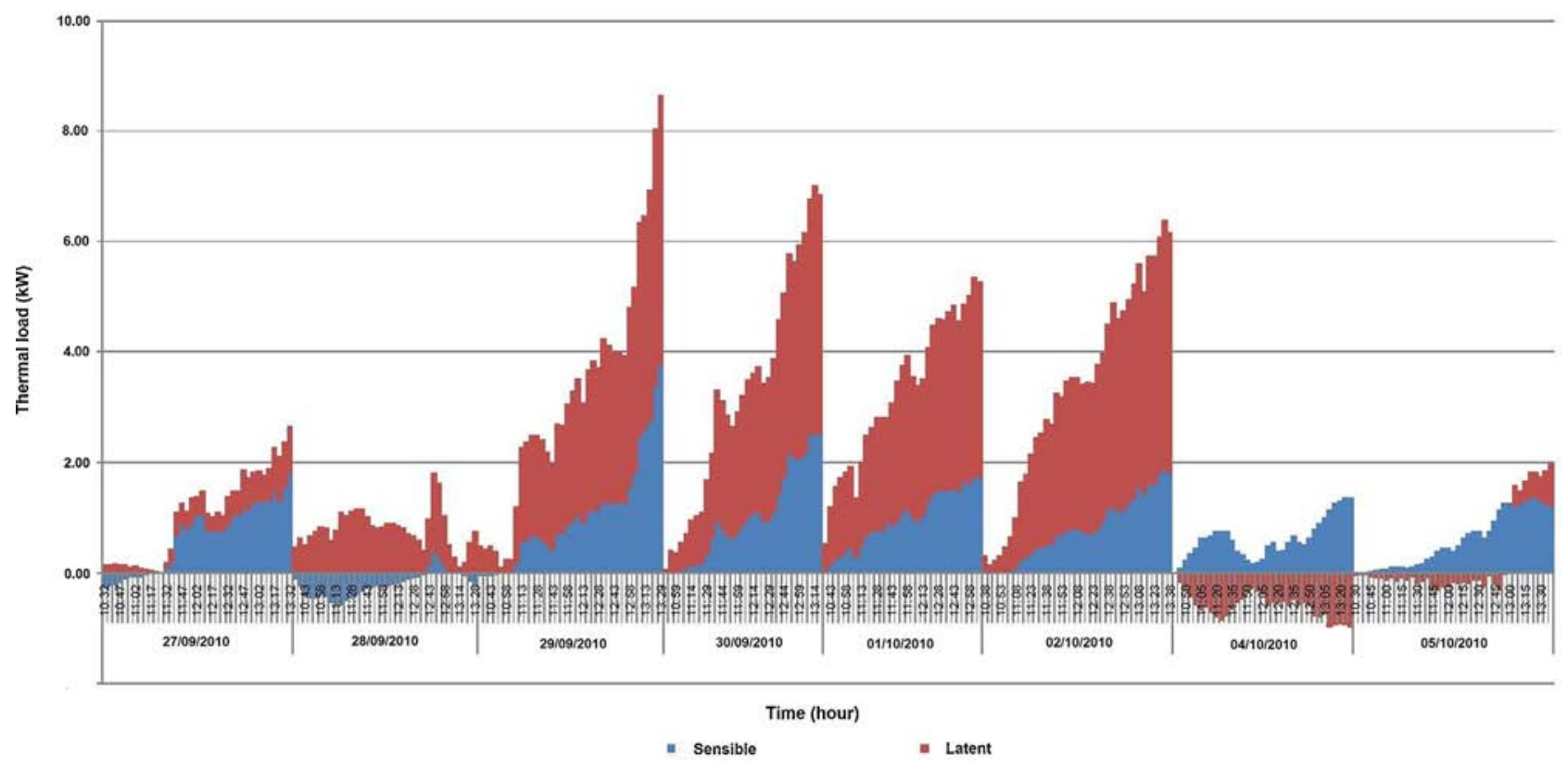

Fig. 11. Hourly evolution of thermal load.

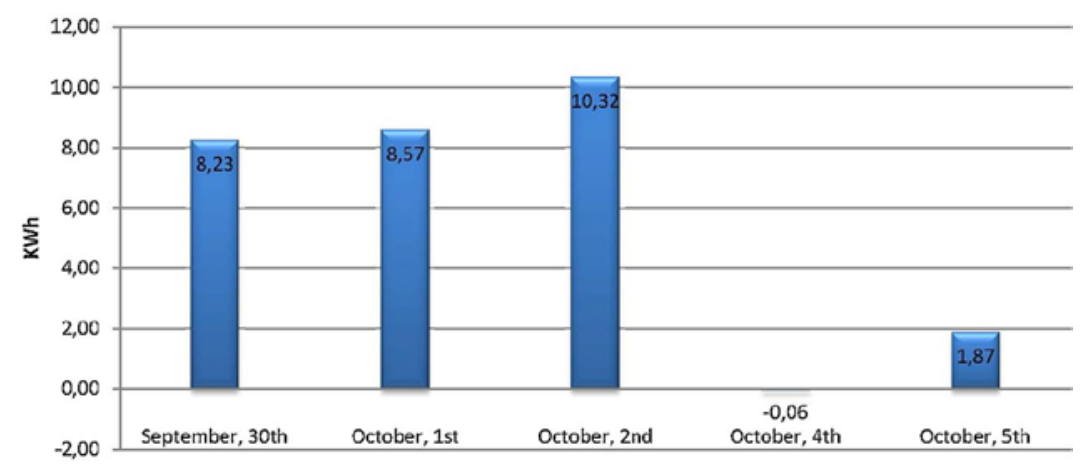

Fig. 12. Cooling loads daily estimation. 
loads are discounted, the outside thermal load that is neutralized in this case is $39.34-37.7=1.64 \mathrm{~kW} \mathrm{~h}$, and shows the impact of the infiltration outdoor air not sealed by the curtain. Using the aforementioned expression of the efficiency ry of the curtain, this means that the installed curtain has an efficiency of $94.30 \%$.

\section{Conclusions}

In warm and humid climates the use of direct expansion cooling machines for shops air conditioning always leads to high electrical consumption. This fact alone would justify the use of climate separators in these climates, for all type of buildings, provided that a high frequency of doors opening and closing is expected.

Using conventional air curtains does not necessarily bring savings. Even at maximum power supply they hardly maintain the desired internal temperature conditions, due to the latent load they have to match.

Experimental data show that using conventional curtains, electrical consumption of the cooling system, due to the extra power demanded by the fan, nearly equals the consumption obtained without the system.

For the case of study, the use of high efficiency air curtains means energy savings of $32.90 \%$ due to:

More than $90 \%$ effectiveness in climate separation, reducing drastically the latent load that has to compensate the chiller.

Lower consumption of the curtain fan, which moves the strict flow in each case to achieve the separation climate.

In winter conditions, air curtains such as those studied are an energy saving potential to operate not only as separators climate but as terminal units of water at low temperatures.

\section{References}

[1] E. Stamper, R. Koral, Handbook of Air Conditioning, Heating and Ventilating, Industrial Press Inc., New York, NY, 1979, pp. 2-111.

[2] N. Brown, J.A. Caeiro, H. Bruhns, A.J. Wright, A.J. Summerfield, T. Oreszczyn, Air conditioning surveys in the UK retail sector, or 'Keeping the cold', in: Proceedings of International Conference on Improving Energy Efficiency in Commercial Buildings, Frankfurt, Germany, 2006.

[3] ASHRAE, Standard 90.1-2007, Energy Standard for Buildings Except Low-rise Residential Buildings, American Society of Heating, Refrigerating and AirConditioning Engineers, Inc., Atlanta, GA, 2006.

[4] J. Castejon-Navas, M.A. Galvez-Huerta, T. Gil-Lopez, V. Gomez-Garcia, Energy savings in hygrothermal conditioning of wide-open workshops with the use of high efficiency air curtains, in: Proceedings of International Conference on Management and Service Science, Shanghai, China, 2012.

[5] European Directive, 2010/31/EU of the European Parliament and of the Council of 19 May 2010 on the energy performance of buildings (recast), Official Journal of the European Union 53 (153) (2010) 13-35.

[6] European, Directive 2012/27/EU of the European Parliament and of the Council of 25 October 2012 on energy efficiency, amending Directives 2009/125/EC and 2010/30/EU and repealing Directives 2004/8/EC and 2006/32/EC, Official Journal of the European Union 55 (315) (2012) 1-56.

[7] J. Castejon-Navas, T. Gil-Lopez, M.A. Galvez-Huerta, V. Gomez-Garcia, Environmental protection and energy savings in HVAC systems from the hygrothermal and air quality standpoints, in: Proceedings of International Conference on Management and Service Science, Wuhan, China, 2011.

[8] ASHRAE, Ventilation, infiltration, indoor air quality for non industrial applications, in: Handbook Fundamentals, American Society of Heating, Refrigerating and Air-Conditioning Engineers, Inc., Atlanta, GA, 2009, pp. 11.17, 12.6, 16.10.

[9] T. Gil-Lopez, J. Castejon-Navas, M.A. Galvez-Huerta, V. Gomez-Garcia, Predicted percentage of dissatisfied and air age relationship in ventilation systems: application to a laboratory, HVAC\&R Research 19 (2013) 7686

[10] M.A. Galvez-Huerta, J. Castejon-Navas, T. Gil-Lopez, V. Gomez-García, Influence of the number and location of the luminaries in the "Predicted Percentage Dissatisfied” of an operating room, in: Proceedings of Internationa Conference on Environmental Pollution and Public Health, Shanghai, China, 2012.

[11] R.D., 1027/2007. Reglamento de Instalaciones Térmicas de Edificios: IT. 1. 1. 4. 1, Building Technical Code, Spanish Government, 2007.

[12] AEMET, State Meteorological Agency, Ministry of the Environment, Rural and Marine Environment Spanish Government, 2011.

[13] R.D. 47/2007, Procedimiento básico para la certificación de eficiencia energética de edificios de nueva construcción, Spanish Government, 2007.

[14] CIBSE, TM46: Energy Benchmarks, The Chartered Institution of Building Services Engineers, London, UK, 2008.

[15] T. Gil-Lopez, M.A. Galvez-Huerta, J. Castejón-Navas, P. O’Donohoe, High efficiency mix energy system design with low carbon footprint for wide-open workshops, in: M. Eissa (Ed.), Energy Efficiency - The Innovative Ways for Smart Energy, the Future Towards Modern Utilities, InTech, 2012, ISBN 978-953-510800-9, DOI: $10.5772 / 2590$.

[16] Biddle Innovative Klimatechnik, VACP (visual air curtain performance) - Luftschleier-Simulation, Gesellschaft mit beschränkter Haftung, Germany, 2012.

[17] W. Gosney, H. Olama, Fully developed flow for doors and gaps with vertical cross section, in: ASHRAE Refrigeration Handbook, American Society of Heating, Refrigerating and Air-Conditioning Engineers, Inc., Atlanta, GA, 2002, pp. 13, Chapter 12

[18] ASHRAE, Nonresidential cooling and heating load calculation, in: Handbook Fundamentals, American Society of Heating, Refrigerating and Air-Conditioning Engineers, Inc., Atlanta, GA, 2009, Chapters $18-28$.

[19] A.M. Foster, M.J. Swain, R. Barrett, P. D’Agaro, S.J. James, Effectiveness and optimum jet velocity for a plane jet air curtain used to restrict cold room infiltration, International Journal of Refrigeration 29 (2006) 692-699.

[20] F. Allard, Y. Utsumi, Airflow through large openings, Energy and Buildings 18 (1992) 133-145

[21] C.J. Chen, W. Rodi, Vertical Turbulent Buoyant Jets: A Review of Experimental Data, Pergamon Press, Oxford, UK, 1990

[22] F.C. Hayes, W.F. Stoecker, Design data for air curtains, ASHRAE Transactions 2121 (1969) 168-180.

[23] A.M. Foster, M.J. Swain, R. Barrett, P. D’Agaro, S.J. James, Experimental verification of analytical and CFD predictions of infiltration through cold stores entrances, International Journal of Refrigeration 26 (2003) 918925.

[24] K. Sirén, Technical dimensioning of a vertically upwards blowing air curtain-Part I, Energy and Buildings 35 (2003) 681-695.

[25] T. Gil-Lopez, M.A. Gálvez-Huerta, J. Castejón-Navas, V. Gómez-García, Analysis of carbon impact using mix energy sources for industrial heating applications: an assessment of options to refit services in an existing building, Fuel Processing Technology 103 (2012) 151-159. 